\title{
Genetic composition of the Ascension Island green turtle rookery based on mitochondrial DNA: implications for sampling and diversity
}

\author{
Angela Formia ${ }^{1,4, *}$, Annette C. Broderick ${ }^{2}$, Fiona Glen ${ }^{2,3}$, Brendan J. Godley ${ }^{2}$, \\ Graeme C. Hays ${ }^{3}$, Michael W. Bruford ${ }^{1}$ \\ ${ }^{1}$ Biodiversity and Ecological Processes Research Group, School of Biosciences, Cardiff University, Cardiff CF10 3TL, UK \\ ${ }^{2}$ Marine Turtle Research Group, Centre for Ecology and Conservation, School of Biosciences, University of Exeter, \\ Cornwall Campus, Penryn TR10 9EZ, UK \\ ${ }^{3}$ School of Biological Sciences, Institute of Environmental Sustainability, University of Wales Swansea, Singleton Park, \\ Swansea SA2 8PP, UK
}

${ }^{4}$ Present address: Dipartimento di Biologia Animale e Genetica, University of Florence, Via Romana 17, 50125 Firenze, Italy

\begin{abstract}
In species of conservation concern it is often difficult to be certain that population diversity and structure have been adequately characterised by genetic sampling. Since practical and financial constraints tend to be associated with increasing sample sizes in many conservation genetic studies, it is important to consider the potential for sampling error and bias due to inadequate samples or spatio-temporal structure within populations. We analysed sequence data from the mitochondrial DNA control region in a large sample $(n=245)$ of green sea turtles Chelonia mydas collected at the globally important rookery of Ascension Island, South Atlantic. We examined genetic diversity and structure among 10 sampling sites, 4 beach clusters and 4 nesting seasons, and evaluated the genetic composition of Ascension against other Atlantic nesting populations, including the wellstudied rookery at Tortuguero (Costa Rica). Finally, we used rarefaction and GENESAMP analyses to assess the ability of different sample sizes to provide acceptable genetic representations of a population, using Ascension and Tortuguero as models. On Ascension, we found 13 haplotypes, of which only 3 had been previously observed in the rookery, and 5 previously undescribed. We detected no differentiation among beach clusters or sampling seasons, and only weak differentiation among the 3 primary nesting sites. The increased sample size for Ascension provided higher resolution and statistical power in describing genetic structure among all other known Atlantic rookeries. Our extrapolations showed that a maximum of 18 and 6 haplotypes are expected to occur in Ascension and Tortuguero, respectively, and that current sample sizes are sufficient to describe most of the variation. We recommend using rarefaction and GENESAMP analyses on a rookery-by-rookery basis to evaluate whether a sample set adequately describes mitochondrial DNA diversity, thus strengthening subsequent phylogeographic and mixed stock analyses, and management recommendations for conservation.
\end{abstract}

KEY WORDS: Chelonia mydas · Control region · Sequences · Haplotypes · Analysis of variance · Rarefaction analysis

Resale or republication not permitted without written consent of the publisher

\section{INTRODUCTION}

Due to the philopatric behaviour of females (Meylan et al. 1990, Allard et al. 1994), marine turtle populations tend to be structured along female lineages. In light of the matrilineal inheritance of mitochondrial
DNA (mtDNA), analyses of this genetic marker can therefore be useful in sea turtle phylogeographic studies (Bowen et al. 1992, 1994, 1998, Dutton et al. 1999). However, as for other marine vertebrates (O'CorryCrowe et al. 1997, Graves 1998, Rosel et al. 1999, Escorza-Treviño \& Dizon 2000, Duncan et al. 2006), the 
control region haplotype distribution in Atlantic green turtles Chelonia mydas tends to be characterised by few common haplotypes and numerous rare ones (Lahanas et al. 1994, Encalada et al. 1996, Formia et al. 2006). In such cases, sampling error may bias analysis, and small sample sizes can greatly reduce resolution, the ability to discriminate between populations and the power to detect rare or unique haplotypes. To assess the extent of this potential error, increased sampling of green turtle populations in the Atlantic and worldwide is currently a high research priority.

Green turtles are listed as globally endangered by the World Conservation Union (IUCN) (Baillie et al. 2004) and it is essential to elucidate many aspects of their life cycles that are insufficiently understood. Although the most important nesting sites in the Atlantic have been identified (Seminoff 2004), genetic data on their composition are still incomplete and several haplotypes found in foraging ground samples have yet to be detected in any rookeries (Bass \& Witzell 2000, Formia 2002, Bagley 2003, Luke et al. 2004). This lack of information may hinder our ability to use baseline genetic data from nesting populations in mixed stock analysis to assess the composition of foraging stocks present in feeding habitats or resulting from direct or incidental capture in fisheries (e.g. Bowen et al. 1995, Bass et al. 1998, Lahanas et al. 1998, Laurent et al. 1998, Luke et al. 2004). Because of the important conservation implications of mixed stock analysis, it is essential for nesting stock information to be as complete and as accurate as possible.

While it is well known that the green turtle life cycle involves movements over vast spatial and temporal scales (Musick \& Limpus 1997, Plotkin 2003), the precision of natal homing and the extent of nest-site fidelity from one breeding season to the next are still under scrutiny. Hence, it is often difficult to assess the nesting range of a population and estimate the number and geographic extent of management units needed for conservation. Studies using tagging and genetic analysis have reported that individuals return to nest sites with varying degrees of precision (e.g. Allard et al. 1994, Miller 1997, Dethmers et al. 2006, Lee et al. 2007). For instance, the same tagged female was found nesting in both Europa and Tromelin (Indian Ocean), a distance of $2200 \mathrm{~km}$ apart (Le Gall \& Hughes 1987). On the other hand, Caribbean green turtles exhibit sitespecific philopatry at local scales as shown by genetic analysis (Allard et al. 1994, Peare \& Parker 1996), and flipper-tagged individuals often return to within a few hundred meters of the same site in successive nesting seasons (Carr \& Hirth 1962, Carr \& Carr 1972, Hirth 1997, Miller 1997). Dethmers et al. (2006) used extensive mitochondrial and mark-recapture data from Australasia to infer that gene flow between rookeries within $500 \mathrm{~km}$ is not uncommon and that proximate rookeries can be grouped into single management units.

Bjorndal et al. (2005) reported on the genetic composition of Tortuguero (Costa Rica), the largest nesting population in the Atlantic (Seminoff 2004). Using mtDNA haplotypes of 433 samples, they did not find genetic structure either spatially, along the $30 \mathrm{~km}$ nesting beach, or temporally, within and among nesting seasons. In addition, they concluded that Tortuguero exhibits haplotype and nucleotide diversities that are lower than those of other rookeries in the Caribbean. While previous work had only reported genetic samples from 41 nesting females (Encalada et al. 1996, Lahanas et al. 1998), Bjorndal et al. (2005) demonstrated the value of an increased sample size, revealing 3 additional haplotypes, 2 of which had been previously found only at foraging grounds. The authors highlighted that the new results substantially altered mixed stock analyses in foraging aggregations in the region and the relative contributions of the Tortuguero rookery, due to changes in haplotype frequencies and the discovery of haplotypes not previously found among nesting individuals (Bjorndal et al. 2005).

Here, we present a comprehensive dataset from Ascension Island, the second largest green turtle rookery in the Atlantic (Broderick et al. 2006), for which substantially smaller sample sizes are available to date (Encalada et al. 1996, Formia et al. 2006). Ascension is a volcanic island located in the southern Atlantic Ocean, approximately $1500 \mathrm{~km}$ from West Africa and $2200 \mathrm{~km}$ from Brazil. The remoteness of this oceanic rookery has raised several considerations regarding long-distance navigation and selection of nesting sites (Carr \& Hirth 1962, Koch et al. 1969, Carr \& Coleman 1974, Bowen et al. 1989, Papi et al. 1995, 2000, Luschi et al. 1998, Lohmann et al. 2001, Hays et al. 2003) and analysis of genetic structure may contribute to elucidating patterns. In this study, we examined mtDNA control region haplotypes and diversity in the Ascension Island green turtle rookery in order to (1) examine genetic structure within a single nesting population and evaluate any spatial or temporal patterns; (2) compare the genetic composition of Ascension to that of other Atlantic rookeries, assessing the effect of sample size; and (3) Evaluate the sampling effort needed to adequately describe genetic variation of this population using the mtDNA control region.

\section{MATERIALS AND METHODS}

Sampling and study site. The length of the Ascension Island beaches is approximately $6 \mathrm{~km}$ in total, scattered around the north, northeast and southwest 
coasts of the island, which has an approximate area of only $90 \mathrm{~km}^{2}$. We classified the beaches following Mortimer \& Carr (1987) into 10 sampling sites consisting of single beaches or groups of small coves (Fig. 1). Samples were collected during daily monitoring of these sites. Sampling was random within each beach and hatchlings were sampled based on their date of emergence from the nest. However, sampling effort could not be uniform for all seasons and sites due to logistical constraints and variation in nesting density between beaches. Approximately $50 \%$ of all nesting is concentrated at 3 primary beaches: Beach 1 (South West Bay), Beach 12 (Long Beach) and Beach 27 (North East Bay) (Mortimer \& Carr 1987, Godley et al. 2001).

We collected a total of 247 samples, 130 from nesting females, and hatchlings from 117 different nests. Results from 50 of these samples selected at random are reported in Formia et al. (2006). We sampled during 4 consecutive nesting seasons (December to May): 1998 to 1999 (79 samples), 1999 to 2000 (30 samples), 2000 to 2001 (80 samples) and 2001 to 2002 (58 samples), referred to here as Years 1, 2, 3 and 4, respec-

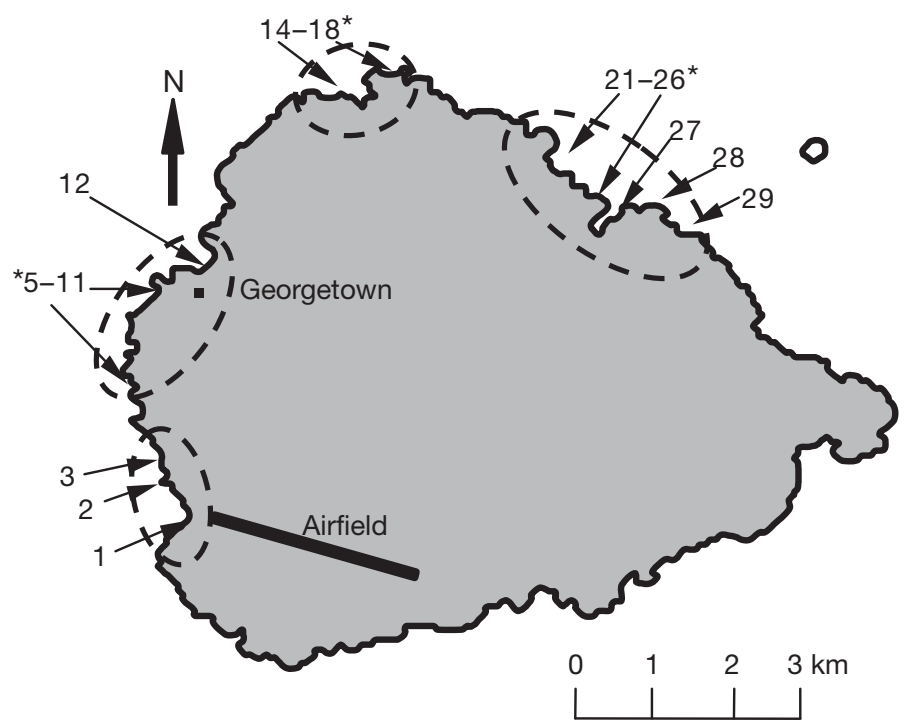

Fig. 1. The 10 sampling sites of our study at Ascension Island: Beach 1 (South West Bay), Beach 2 (Turtleshell), Beach 3 (Clarke's), Beach 5-11 (Mitchell's Cove-Georgetown), Beach 12 (Long Beach), Beach 14-18 (English Bay), Beach 21-26 (Porpoise Point), Beach 27 (North East Bay), Beach 28 (Beach Hut), and Beach 29 (Hannay). Numbering system and beach descriptions can be found in Mortimer \& Carr (1987) and Godley et al. (2001); asterisks indicate the pooling of 5 to 7 small coves or beaches into a single sampling site (as per previous studies). Beach clusters as defined by Mortimer \& Portier (1989) are shown by the dashed lines. Sample sizes for the 4 consecutive nesting seasons are, respectively, as follows: Beach $1(12,0,9,0)$; Beach $2(0,0,6,0)$; Beach $3(0,0,10,0)$; Beach 5-11 (0, 0, 9, 20); Beach $12(23,30,11,0)$; Beach 14-18 $(0,0,9,18)$; Beach 21-26 (0, 0, 9, 20); Beach $27(44,0,4,0)$; Beach $28(0,0,4,0)$; Beach $29(0,0,9,0)$ tively. Hatchlings were sampled during a $13 \mathrm{~d}$ interval in each of Years 3 and 4 and were found dead in nests excavated on the first day following emergence; identity of individual mothers was unknown and only one hatchling was collected per nest. Females in Years 1, 2 and 4 were sampled during oviposition and tagged. Sampling procedures were modified from Dutton (1996) and were designed to minimise disturbance. Biopsies of approximately $5 \mathrm{~mm}$ diameter were taken from the anterior flipper and stored in $20 \% \mathrm{wt} / \mathrm{vol}$ dimethyl sulfoxide (DMSO) in saturated $\mathrm{NaCl}$ at ambient temperature.

Resampling probability. For hatchlings, the resampling probability was very low. Approximately $7 \%$ of breeding females had a remigration interval of $2 \mathrm{yr}$, and $40.6 \%$ had a remigration interval of $3 \mathrm{yr}$ (Mortimer \& Carr 1987). Thus, hatchlings sampled in Years 3 and 4 could possibly belong to females sampled in Year 1 or Year 2. However, given that an estimated 1500 to 2000 females nested in Year 3 and that 4000 to 5000 nested in Year 4 (Broderick et al. 2006), we assumed that the probability of double sampling one or more hatchlings between seasons could be ignored. Within seasons (Years 3 and 4), the probability of resampling hatchlings from the same female was minimised by collecting samples from nests hatched during a $13 \mathrm{~d}$ period, a typical inter-nesting interval, the time between subsequent clutches by the same female in the same season (Mortimer \& Carr 1987). We also sampled at each of the 10 beaches for less than $9 \mathrm{~d}$. Given probable site fidelity (Mortimer \& Portier 1989) and the magnitude of the nesting population, the resultant resampling probability was likely close to zero.

Laboratory analysis. Samples were macerated and digested with Proteinase-K at $37^{\circ} \mathrm{C}$ overnight. DNA was extracted using a standard phenol:chloroform protocol (Milligan 1998) followed by ethanol precipitation, or using a modification of the protocol by Allen et al. (1998). A 486 base pair fragment of the mtDNA control region was amplified using primers LTCM1 and HDCM1 (Allard et al. 1994). Polymerase chain reactions (PCR) consisted of $1.5 \mathrm{mM} \mathrm{MgCl}_{2}, 1 \mathrm{X}$ PCR buffer, $200 \mu \mathrm{M}$ each dNTP, $0.5 \mu \mathrm{M}$ each primer, $0.5 \mathrm{U}$ Gibco BRL Taq, $1 \mu$ template DNA and $\mathrm{H}_{2} \mathrm{O}$ to a total volume of $10 \mu \mathrm{l}$. PCR was carried out in a GeneAmp PCR System 9700 (Perkin Elmer) for $3 \mathrm{~min}$ at $94^{\circ} \mathrm{C}$, followed by 35 cycles of $45 \mathrm{~s}$ at $94^{\circ} \mathrm{C}, 30 \mathrm{~s}$ at $55^{\circ} \mathrm{C}, 1.5 \mathrm{~min}$ at $72^{\circ} \mathrm{C}$, and $10 \mathrm{mi}$ at $72^{\circ} \mathrm{C}$. PCR products were cleaned using a Geneclean Turbo Kit (Bio 101), then sequenced in both directions with the ABI Prism Big Dye Terminator Cycle Sequencing kit Versions 2 and 3 (Applied Biosystems). The sequencing reaction used $1.5 \mu \mathrm{l}$ template, $1.5 \mu$ l unlabelled primer, $0.5 \mu \mathrm{l} \mathrm{ABI}$ Big Dye Ready Reaction mix (Applied Biosystems), $2.5 \mu \mathrm{l}$ 
BetterBuffer (Web Scientific) and $1.5 \mu \mathrm{H}_{2} \mathrm{O}$, and was carried out under the following conditions: 25 cycles of $10 \mathrm{~s}$ at $96^{\circ} \mathrm{C}, 5 \mathrm{~s}$ at $50^{\circ} \mathrm{C}$ and $4 \mathrm{~min}$ at $60^{\circ} \mathrm{C}$. After isopropanol precipitation, samples were analysed with an Applied Biosystems 3100 Sequencer. Sequences were aligned and edited using Sequencher 3.1.2 (Gene Codes Corporation).

Data analysis. The program TCS V. 1.13 (Clement et al. 2000) was used to assess relationships among haplotypes and to calculate a matrix showing the number of substitutions distinguishing sequences. Haplotype and nucleotide diversity were calculated for each beach and for the entire island using Arlequin V. 2.0 (Schneider et al. 2000).

We evaluated spatial structure within the population by pairwise comparisons of genetic differentiation and nested analysis of molecular variance (AMOVA, Excoffier et al. 1992) to partition the variation within and among beaches using Arlequin. We grouped samples according to the 4 beach clusters established by Mortimer \& Portier (1989) to assess whether genetic structure reflected the site-fidelity suggested by tag returns in that study. We also checked for temporal structure by comparing differentiation among the 4 sampling seasons. However, these results should be interpreted with caution since beaches were sampled unevenly over the years; for instance, all beaches were sampled in Years 1 and 3, only Beach 12 was sampled in Year 2, and only Beaches 5 to 11,14 to 18 and 21 to 26 were sampled in Year 4. Due to this sampling heterogeneity, we did not test for variation within a single season. Arlequin enables calculation of $\Phi$-statistics using a model of genetic distance and a gamma parameter estimate (Excoffier et al. 1992), as well as conventional F-statistics analogous to $\theta$ (Weir \& Cockerham 1984) under a model of equal genetic distance. We used the Kimura 2-parameter correction (Kimura 1980) when computing distance matrices among haplotypes, which allows multiple substitutions per site and takes into account different evolutionary rates of transitions and transversions. Significance values were obtained from 10100 permutations, and sequential Bonferroni corrections were applied (Rice 1989).

We assessed population differentiation between Ascension Island and other Atlantic rookeries, as well as among successive sampling studies carried out in Ascension. We compared our data to the results of Encalada et al. (1996) based on 20 samples collected in 1990 , to the random subset of our samples reported by Formia et al. (2006), to the well-sampled Tortuguero population (Encalada et al. 1996, Lahanas et al. 1998, Bjorndal et al. 2005), as well as to other Atlantic rookeries (Lahanas et al. 1994, Encalada et al. 1996). We focused on Tortuguero in subsequent comparative analyses because of its global importance, its large population size and the large mitochondrial dataset available.

We applied rarefaction analysis to determine the relationship between sample size and the number of detected haplotypes for the overall rookery and individual beaches. Rarefaction was initially designed to compare species diversity within habitat types with uneven sampling effort (Sanders 1968, Hurlbert 1971, Simberloff 1972). It can be used to calculate the average expected number of variants in a sample set by taking hypothetical subsamples from a larger collection, and to assess whether different subsamples can be expected to belong to the same parent population (Simberloff 1978). Recognising that differences in sample size among sites can confound the comparison of genetic diversity, several studies have applied rarefaction (or a similar combinatorial approach) to the study of genetic variation (Hebert et al. 1988, Bernatchez et al. 1989, Lehman \& Wayne 1991, Epifanio et al. 1995, Altmann et al. 1996, Kohn et al. 1999, Leberg 2002, Kalinowski 2004). We used the program Rarefaction Calculator (J. Brzustowski, www2.biology.ualberta.ca/ jbrzusto/rarefact.php) to calculate the rarefaction curve, the expected number of haplotypes in subsamples taken at random from the total collection, with successive subsamples increasing by one. We used a total of 245 individuals in the collection and thus considered subsamples changing incrementally from 1 to 245. We then used SPSS V. 11.0.1 to fit this curve to the Michaelis-Menten equation, a commonly used asymptotic model (Colwell \& Coddington 1994): $S(n)=$ $\left(S_{\max } n\right) /(B+n)$, where $S(n)$ is the number of haplotypes as a function of sample size $n, S_{\max }$ is the asymptote, and $B$ is the rate of decline of the slope. Assuming that a finite total number of haplotypes occurs in the rookery and is represented by the asymptote, it was possible to assess the sample size needed to detect a desired proportion of the haplotype variation.

However, because it is based on haplotype numbers rather than identity, rarefaction analysis does not make predictions based on the relative frequency of a haplotype with respect to population size, nor does it identify the components of diversity. Using the program GENESAMP (Sjögren \& Wyöni 1994, Barratt et al. 1999) we analysed the probability of detection of common and rare haplotypes given our total sample size and an approximate population size of 9000 to 20000 nesting females (estimated from data in Broderick et al. 2002, assuming 3 clutches per season and 3 to 4 yr remigration intervals). Therefore, we were able to evaluate the resolution of our sample set by determining the sample size required to detect a haplotype at a specified frequency and with a defined probability. 


\section{RESULTS}

\section{Genetic diversity}

Of the 247 samples amplified, 2 exhibited possible heteroplasmy and were excluded from subsequent analysis. The remaining 245 samples comprised 13 haplotypes (Table 1). Most of these haplotypes had been previously described and assigned to a standard classification referenced at http://accstr.ufl.edu/genetics.html (Lahanas et al. 1994, Encalada et al. 1996, K.
A. Bjorndal \& A. B. Bolten unpubl.). However, haplotypes CM-A39, CM-A44, CM-A45, CM-A46 and CMA50 had not been previously characterised and were therefore submitted to GenBank (accession numbers AY044852, AY861466 and AF529025 to AF529027, respectively).

By far the most common haplotype in Ascension Island was CM-A8, occurring in $83 \%$ of samples, while CM-A6, CM-A9, CM-A10 and CM-A24 each occurred in 2 to $4 \%$ of the samples; the remainder were observed in only 1 or 2 individuals (Table 2). Analyses

Table 1. Nine polymorphic sites within the 486 bp sequence defining 13 haplotypes. Polymorphisms include 11 transitions and 1 transversion (underlined). Haplotype CM-A25 exhibits a 10-base insertion (CAATGGGTTG) at position 463. Base positions are shown based on a scale of 0 to 486, using CM-A8 as a reference sequence, and based on alignment with the complete green turtle mtDNA sequence of 16497 nucleotides (Kumazawa \& Nishida 1999; accession number ABO12104). •: same as bp in $\mathrm{CM}-\mathrm{A} 8$; +: insert; /: no insert

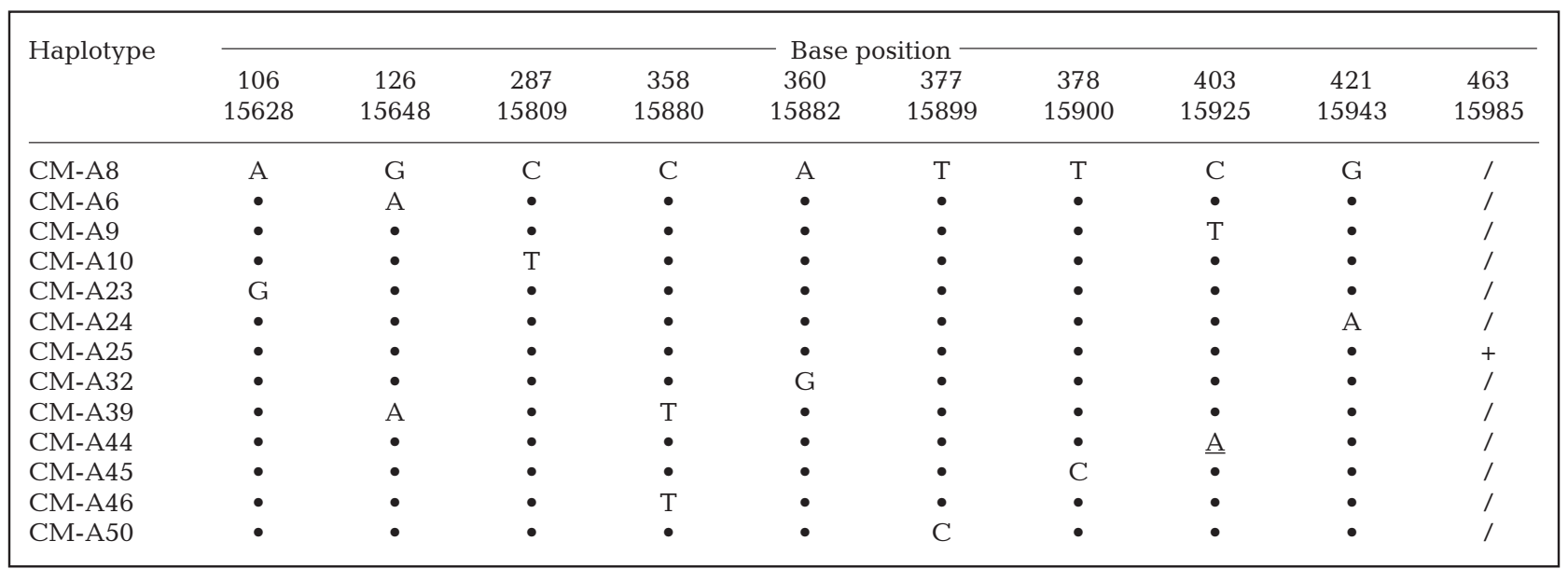

Table 2. Haplotype distribution by beach, proportional frequencies (Freq.), haplotype $(\hat{\mathrm{h}})$ and nucleotide diversities $(\pi) \pm \mathrm{SD}$

\begin{tabular}{|c|c|c|c|c|c|c|c|c|c|c|c|}
\hline & $\begin{array}{c}\text { Beach } \\
1\end{array}$ & $\begin{array}{c}\text { Beach } \\
2\end{array}$ & $\begin{array}{c}\text { Beach } \\
3\end{array}$ & $\begin{array}{c}\text { Beach } \\
5-11\end{array}$ & $\begin{array}{c}\text { Beach } \\
12\end{array}$ & $\begin{array}{l}\text { Beach } \\
14-18\end{array}$ & $\begin{array}{l}\text { Beach } \\
21-26\end{array}$ & $\begin{array}{l}\text { Beach } \\
27\end{array}$ & $\begin{array}{c}\text { Beach } \\
28\end{array}$ & $\begin{array}{c}\text { Beach } \\
29\end{array}$ & Freq. \\
\hline CM-A6 & & & & 1 & 6 & 1 & 2 & 1 & & & 0.045 \\
\hline CM-A8 & 20 & 6 & 8 & 24 & 46 & 24 & 23 & 42 & 4 & 7 & 0.833 \\
\hline CM-A9 & & & 1 & 1 & 5 & & & 2 & & & 0.037 \\
\hline CM-A10 & & & 1 & 1 & & 1 & 1 & 1 & & & 0.021 \\
\hline CM-A23 & & & & & & & 1 & & & & 0.004 \\
\hline CM-A24 & & & & 1 & 5 & & 1 & & & & 0.029 \\
\hline CM-A25 & & & & & & 1 & & & & & 0.004 \\
\hline CM-A32 & & & & & & & & & & 1 & 0.004 \\
\hline CM-A39 & & & & & & & & 1 & & & 0.004 \\
\hline CM-A44 & & & & & & & & & & 1 & 0.004 \\
\hline CM-A45 & & & & & & & & 1 & & & 0.004 \\
\hline CM-A46 & & & & & 2 & & & & & & 0.008 \\
\hline CM-A50 & & & & 1 & & & & & & & 0.004 \\
\hline $\mathrm{n}$ & 20 & 6 & 10 & 29 & 64 & 27 & 28 & 48 & 4 & 9 & \\
\hline Haplotypes & 1 & 1 & 3 & 5 & 5 & 4 & 5 & 6 & 1 & 3 & \\
\hline$\hat{\mathrm{h}}$ & $\begin{array}{c}0.000 \\
\pm 0.000\end{array}$ & $\begin{array}{c}0.000 \\
\pm 0.000\end{array}$ & $\begin{array}{c}0.378 \\
\pm 0.181\end{array}$ & $\begin{array}{c}0.320 \\
\pm 0.112\end{array}$ & $\begin{array}{c}0.469 \\
\pm 0.072\end{array}$ & $\begin{array}{c}0.214 \\
\pm 0.103\end{array}$ & $\begin{array}{c}0.328 \\
\pm 0.112\end{array}$ & $\begin{array}{c}0.236 \\
\pm 0.081\end{array}$ & $\begin{array}{c}0.000 \\
\pm 0.000\end{array}$ & $\begin{array}{c}0.417 \\
\pm 0.191\end{array}$ & \\
\hline$\pi$ & $\begin{array}{c}0.0000 \\
\pm 0.0000\end{array}$ & $\begin{array}{c}0.0000 \\
\pm 0.0000\end{array}$ & $\begin{array}{c}0.0008 \\
\pm 0.0009\end{array}$ & $\begin{array}{c}0.0007 \\
\pm 0.0008\end{array}$ & $\begin{array}{c}0.0011 \\
\pm 0.0010\end{array}$ & $\begin{array}{c}0.0003 \\
\pm 0.0005\end{array}$ & $\begin{array}{c}0.0007 \\
\pm 0.0008\end{array}$ & $\begin{array}{c}0.0006 \\
\pm 0.0007\end{array}$ & $\begin{array}{c}0.0000 \\
\pm 0.0000\end{array}$ & $\begin{array}{c}0.0009 \\
\pm 0.0010\end{array}$ & \\
\hline
\end{tabular}


using statistical parsimony revealed that all haplotypes were distinguished from CM-A8 by 1 substitution, except CM-A39 which was distinguished by 2 substitutions. Beaches 12 and 27, when combined, exhibited 8 of the haplotypes, in $46 \%$ of the total sample (112 of 245).

Overall values of haplotype diversity among our 245 Ascension samples were comparable to those of previous studies, including the 20 samples analysed by Encalada et al. (1996) and the subset of 50 in Formia et al. (2006) (Table 3). However, with increasing sample size, the confidence interval around the estimate became narrower. Haplotype diversity in Ascension was virtually double that of Tortuguero (Bjorndal et al. 2005). Interestingly, Beach 12 had the highest haplotype diversity on Ascension, based on 64 samples, while Beach 29 had a similar value with only 9 samples (Table 2). Overall, nucleotide diversity was comparable to that found previously in Ascension (Table 3), but was more than 5 times lower than in Tortuguero (Bjorndal et al. 2005).

Table 3. Haplotype distribution, haplotype (h) and nucleotide diversities $(\pi) \pm \mathrm{SD}$ for the recent Tortuguero sample set (Bjorndal et al. 2005) and 3 Ascension analyses with increasing sample sizes (a: Encalada et al. 1996; b: Formia et al. 2006; c: this study, including Formia et al. 2006)

\begin{tabular}{|c|c|c|c|c|}
\hline \multirow[t]{2}{*}{ Haplotype } & \multirow[t]{2}{*}{ Tortuguero } & \multicolumn{3}{|c|}{ Ascension } \\
\hline & & a & $\mathrm{b}$ & C \\
\hline CM-A3 & 395 & & & \\
\hline CM-A4 & 1 & & & \\
\hline CM-A5 & 32 & & & \\
\hline CM-A6 & & & 3 & 11 \\
\hline CM-A8 & & 16 & 43 & 204 \\
\hline CM-A9 & & 1 & & 9 \\
\hline CM-A10 & & 3 & & 5 \\
\hline CM-A20 & 2 & & & \\
\hline CM-A21 & 3 & & & \\
\hline CM-A23 & & & & 1 \\
\hline CM-A24 & & & 1 & 7 \\
\hline CM-A25 & & & & 1 \\
\hline CM-A32 & & & & 1 \\
\hline CM-A39 & & & 1 & 1 \\
\hline CM-A44 & & & & 1 \\
\hline CM-A45 & & & 1 & 1 \\
\hline CM-A46 & & & 1 & 2 \\
\hline CM-A50 & & & & 1 \\
\hline $\mathrm{n}$ & 433 & 20 & 50 & 245 \\
\hline Haplotypes & 5 & 3 & 6 & 13 \\
\hline$\hat{\mathrm{h}}$ & $\begin{array}{c}0.163 \pm \\
0.023\end{array}$ & $\begin{array}{c}0.353 \pm \\
0.123\end{array}$ & $\begin{array}{c}0.260 \pm \\
0.081\end{array}$ & $\begin{array}{c}0.303 \pm \\
0.038\end{array}$ \\
\hline$\pi$ & $\begin{array}{c}0.0037 \pm \\
0.0024\end{array}$ & $\begin{array}{c}0.0008 \pm \\
0.0008\end{array}$ & $\begin{array}{c}0.0006 \pm \\
0.0007\end{array}$ & $\begin{array}{c}0.0007 \\
0.0008\end{array}$ \\
\hline
\end{tabular}

\section{Population structure}

All $\Phi_{\mathrm{ST}}$ calculations based on genetic distance and no gamma correction yielded results similar to conventional $F_{\mathrm{ST}}$ estimates based on haplotype frequencies only and are not shown here. We carried out pairwise comparisons among all 10 Ascension sampling sites, and 2 out of the 45 pairwise comparisons were found to be significant following Bonferroni correction (Rice 1989) - Beaches 1 and $12\left(F_{\mathrm{ST}}=0.0971, \mathrm{p}=0.013\right)$, and Beaches 12 and $27\left(F_{\mathrm{ST}}=0.0422, \mathrm{p}=0.021\right)$ - although sample sizes were uneven. Beaches 1 and 27 were not genetically differentiated ( $p>0.05)$. An AMOVA of the 3 primary beaches $(1,12$ and 27 ) indicated that $5.26 \%$ $(p=0.006)$ of the variation was partitioned among them, while the remainder was found within each beach. However, AMOVA of the 4 beach clusters showed no significant differences among them $\left(F_{\mathrm{ST}}=\right.$ $0.0126, \mathrm{p}=0.223)$, with the vast majority of the variation partitioned within beaches $(98.74 \%)$. None of the pairwise comparisons between the sampling seasons were significantly different (AMOVA $\mathrm{p}=0.658$ ).

We compared the haplotype frequencies found with different sample sizes in Ascension and Tortuguero, and assessed any corresponding changes in differentiation between the 2 sites (Table 4). The 20 Ascension samples studied by Encalada et al. (1996) were significantly differentiated from the 50 samples in Formia et al. (2006), from the additional 195 samples in this study, and from the combined 245 samples ( $p<0.001$ ); there was no significant differentiation among the latter 3 sample sets (Table 4). For comparison, we carried out a similar analysis of Tortuguero data, a large but less diverse rookery in the Caribbean. We found no significant differentiation among a set of 15 samples (Encalada et al. 1996), 41 samples (including the previous 15; Lahanas et al. 1998), 392 new ones (Bjorndal et al. 2005) and the combined set of 433 (Bjorndal et al. 2005) (Table 4). Among the significant $F_{\mathrm{ST}}$ values from pairwise comparisons of Ascension and Tortuguero, we found a decrease in $F_{\mathrm{ST}}$ from calculations using 50 Ascension samples to those using 195, but no substantial change between the use of 195 and 245 samples (Table 4). On the other hand, an increasing Tortuguero sample size led to an increase in $F_{\mathrm{ST}}$ values when comparing this population to the large Ascension dataset (Table 4).

Finally, we compared the $F_{\mathrm{ST}}$ differentiation between several Atlantic rookeries using the Ascension data in Encalada et al. (1996) and the Ascension data reported here (Table 5). We found that all of the comparisons were significant using our frequency data: 4 comparisons increased in level of significance with sample size, and all except one of the $F_{\mathrm{ST}}$ values also increased in magnitude with increasing sample size. 
Table 4. $F_{\mathrm{ST}}$ comparisons based on haplotype frequencies among sample sets of increasing size collected in Ascension and Tortuguero. Asc A: frequencies in Encalada et al. (1996) (samples collected in 1990); Asc B: frequencies in Formia et al. (2006) (samples collected in 1998 to 2002); Asc C: frequencies in this study, excluding Formia et al. (2006) (samples collected in 1998 to 2002); Tort A: frequencies in Encalada et al. (1996) (samples collected in 1990); Tort B: frequencies in Lahanas et al. (1998), including Encalada et al. (1996) (samples collected in 1988 and 1996); Tort C: new frequencies in Bjorndal et al. (2005) (samples collected in 2001 and 2002). ${ }^{* * *} \mathrm{p}<0.001, \mathrm{~ns}=$ not significant

\begin{tabular}{|lccccccc|}
\hline & Asc A & Asc B & Asc C & Asc B + C & Tort A & Tort B & Tort C \\
\hline Asc A & - & & & & & & \\
Asc B & $0.7083^{* * *}$ & - & & & & & \\
Asc C & $0.6774^{* * *}$ & $-0.0034 \mathrm{~ns}$ & - & & & \\
Asc B + C & $0.6870^{* * *}$ & $-0.0061 \mathrm{~ns}$ & $-0.0042 \mathrm{~ns}$ & - & & \\
Tort A & $0.7442^{* * *}$ & $0.7751^{* * *}$ & $0.7183^{* * *}$ & $0.7254^{* * *}$ & - & & \\
Tort B & $0.8456^{* * *}$ & $0.8364^{* * *}$ & $0.7521^{* * *}$ & $0.7545^{* * *}$ & $-0.0207 \mathrm{~ns}$ & - & - \\
Tort C & $0.8030^{* * *}$ & $0.8105^{* * *}$ & $0.7744^{* * *}$ & $0.7733^{* * *}$ & $0.0001 \mathrm{~ns}$ & $0.0237 \mathrm{~ns}$ & $-0.0021 \mathrm{~ns}$ \\
Tort B + C & $0.8140^{* * *}$ & $0.8206^{* * *}$ & $0.7842^{* * *}$ & $0.7824^{* * *}$ & $-0.0032 \mathrm{~ns}$ & $0.0191 \mathrm{~ns}$ & - \\
$\mathrm{n}$ & 20 & 50 & 195 & 245 & 15 & 41 & 392 \\
\hline
\end{tabular}

Thus, while Ascension was not significantly different from Bioko (Equatorial Guinea) and São Tomé based on the small sample size, differentiation became highly significant using the larger sample of 245. Differentiation also became more statistically marked with greater sample size for Guinea Bissau and Rocas Atoll (Brazil). It should be noted that while the Encalada et al. (1996) data were collected over a single season (1990), samples in this study were gathered over 4 (1998 to 2002).

\section{Population sampling}

We carried out rarefaction analysis on the Ascension Island rookery, assuming a random distribution of haplotypes and that our extensive sampling was representative of the rookery as a whole (since genetic structure was non-significant or weak). The rarefaction curve (Fig. 2a) showed the expected haplotype diversity increase with sample size: the first 2 haplotypes could

Table 5. Comparison of $F_{\mathrm{ST}}$ between Ascension ( $\mathrm{n}=20$, frequencies from Encalada et al. [1996]; $\mathrm{n}=245$, frequencies from present study including Formia et al. [2006]) and other Atlantic rookeries (frequencies from Lahanas et al. 1994, Encalada et al. 1996, Formia et al. 2006). Significance values based on 10100 iterations: ${ }^{*} \mathrm{p}<0.05,{ }^{* *} \mathrm{p}<0.01,{ }^{* * *} \mathrm{p}<0.001, \mathrm{~ns}=$ not significant

\begin{tabular}{|lccc|}
\hline \multirow{2}{*}{ Rookery } & Sample size & \multicolumn{2}{c|}{$F_{\text {ST }}$} \\
\cline { 3 - 4 } & & Ascension (20) & Ascension (245) \\
\hline Guinea Bissau & 51 & $0.2307^{* *}$ & $0.7708^{* * *}$ \\
Suriname & 15 & $0.6899^{* * *}$ & $0.7050^{* * *}$ \\
Venezuela & 30 & $0.7438^{* * *}$ & $0.7216^{* * *}$ \\
Florida & 24 & $0.5371^{* * *}$ & $0.6376^{* * *}$ \\
Mexico & 20 & $0.4158^{* * *}$ & $0.5708^{* * *}$ \\
Rocas Atoll (Brazil) & 16 & $0.1280^{*}$ & $0.6165^{* * *}$ \\
Bioko (Equatorial Guinea) & 50 & $0.0588 \mathrm{~ns}$ & $0.7274^{* * *}$ \\
São Tomé & 20 & $0.0241 \mathrm{~ns}$ & $0.6350^{* * *}$ \\
\hline
\end{tabular}

be detected by 6 to 7 samples, 10 haplotypes by 146 to 147 samples, and 12 by 210 to 211 samples. Using nonlinear regression, we obtained a good fit of our data to the Michaelis-Menten equation $\left(\mathrm{R}^{2}=0.981,100\right.$ iterations), with curve parameters of 17.1 for $S_{\max }$ (the asymptote) and 95.1 for $B$ (the rate of decline of the slope) (Fig. 2b). Therefore, rounding up, we estimated that an approximate total of 18 haplotypes occur in Ascension. Based on extrapolation, 72\% (13 haplotypes) of the diversity would be expected to be captured by at least 224 samples, $83 \%$ of the diversity (15 haplotypes) would require around 430 samples, and $94 \%$ (17 haplotypes) would require approximately 1384 samples.

Nine of the 10 sampling sites had observed number of haplotypes within the $95 \%$ confidence limits of the rarefaction curve, the only exception being the 20 samples collected at Beach 1 (Fig. 2a). According to the rarefaction curve, the 20 samples of Beach 1 would be expected to exhibit between 2 and 7 haplotypes, but only 1 haplotype was detected.

For comparative purposes, we ran rarefaction analysis of Tortuguero (Table 3; Bjorndal et al. 2005) and found that the rarefaction curve for this less diverse rookery was much shallower than for Ascension (Fig. 2b). Using a random subset of 250 Tortuguero samples, nonlinear regression of the rarefaction curve estimated $S_{\text {max }}$ to be 4.11 (not shown), and using all 433 samples the asymptote was estimated to be 5.40 . Hence, this analysis suggests that Tortuguero probably has a maximum of 5 to 6 haplotypes. In addition, the fitted regression curve had a lower rate of slope decline, indicating that sampling had nearly 


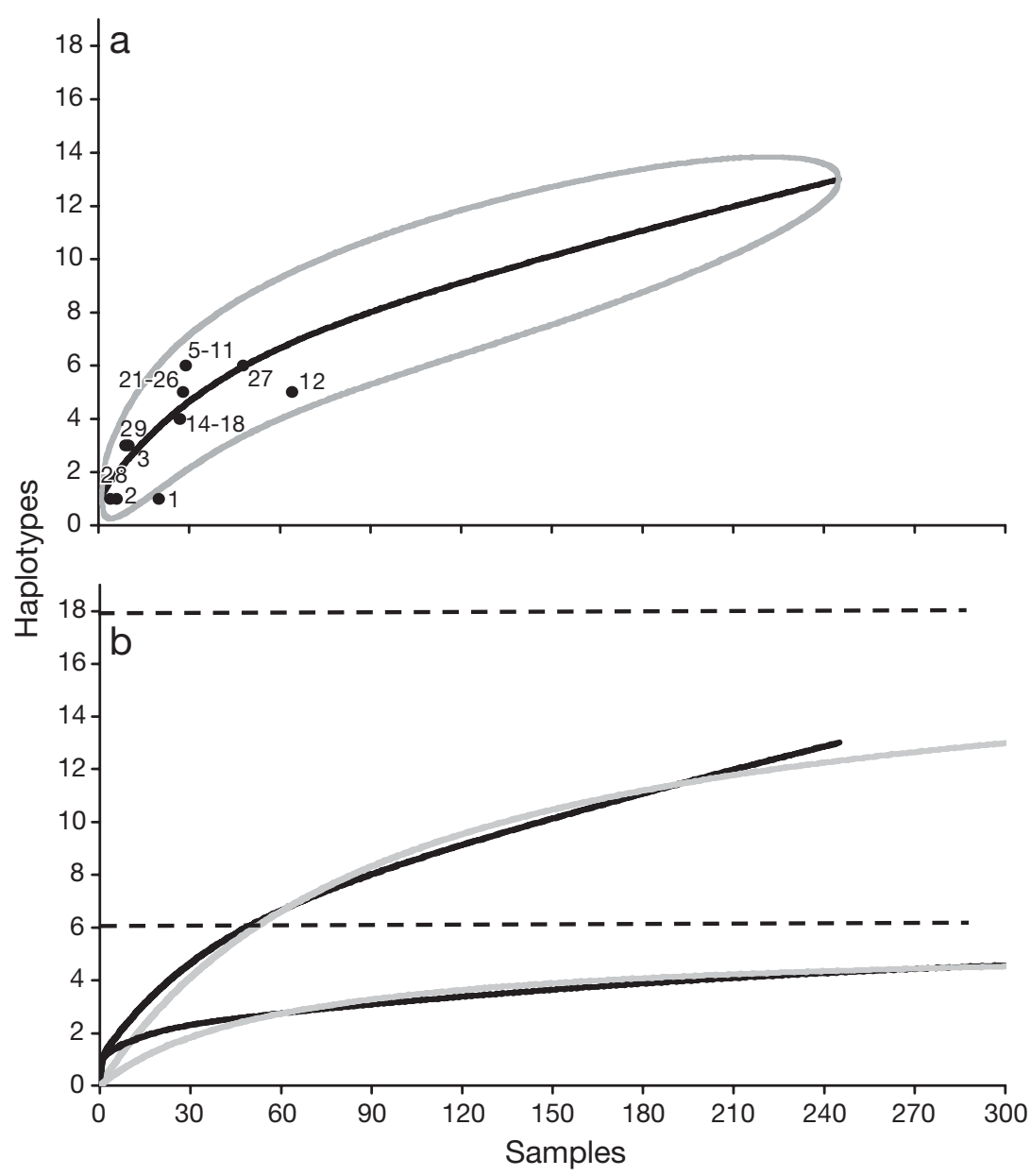

Fig. 2. (a) Rarefaction curve showing the trend of haplotype increase with increasing sample size; the $95 \%$ confidence limits (grey curves) were calculated by multiplying the standard deviation by 1.96 . Points refer to the actual haplotype counts at each beach. (b) Rarefaction curve (black) and fitted sigmoidal curve (grey) for the Ascension Island data (upper curves, $\mathrm{n}=245$ ), and for the Tortuguero data (lower curves, $\mathrm{n}=433$ ). Upper dashed line shows the value of the asymptote for Ascension at 18 haplotypes. Lower dashed line shows the Tortuguero asymptote at 6 haplotypes

reached the asymptotic level; 4 haplotypes could be found with 73 samples, 5 with 167 samples, and 6 with 729 samples. Therefore, we estimated that the available sample size of 433 samples may describe approximately $83 \%$ of the total variation (5 haplotypes detected out of 6 estimated to occur), although the same result could have been attained with a minimum of 167 samples. It is interesting to note that, in both Ascension and Tortuguero, approximately 430 samples would describe about $83 \%$ of the variation.

Given our sample size of 245 for Ascension Island and an estimated population size of 9000 to 20000 nesting females, GENESAMP calculated that a haplotype with a frequency of 0.004 (such as unique haplotypes CM-A23, CM-A25, CM-A32, CM-A39, CM-A44 or CM-A45, CM-A50) would be detected with a proba- bility of approximately $64 \%$. Haplotypes CM-A8, CM-A6, CM-A9, CM-A10 and CM-A24 would be detected with 99 or $100 \%$ probability, while CM-A46 (frequency 0.008 ) would be detected with an estimated probability of $87 \%$. In this sample of 245 individuals, there was a $95 \%$ probability of detecting haplotypes at a minimum frequency of 0.012 . The analysis estimates that a sample of 699 to 717 would be required to have a $95 \%$ chance of detecting haplotypes with a frequency of 0.004 (the rarest haplotypes detected in this study, listed above) in a population the size of Ascension. On the other hand, only 2 samples would be needed to detect CM-A8 with a $95 \%$ probability. For $95 \%$ detection of haplotypes with frequencies between 0.05 and 0.02 (such as CM-A6, CM-A9, CM-A10 and CM-A24) we estimated that we would need 65 to 145 samples, and that 356 to 361 samples would detect a haplotype with a frequency of 0.008 (CMA46). Finally, a sample size of 1384 would detect with $63 \%$ probability haplotypes at a frequency of 0.0007 (17 out of 18 haplotypes, or $94 \%$ of the variation, as estimated by rarefaction analysis).

\section{DISCUSSION}

Early conservation genetics studies often operated with modest sample sizes, usually due to logistical, financial or technical limitiations in the laboratory. Today, with increased automation of molecular techniques, it is pertinent to revisit the biogeographic conclusions made previously and critically examine the level of sampling necessary to optimize the description of haplotype diversity, before rare haplotypes become even more rare in diminishing populations. We also estimated overall and fine-scale diversity in Ascension Island, evaluated within-rookery structure on spatial and temporal scales, and examined the resolution and detection power of our sample sizes in Ascension and the other large, well-described rookery of Tortuguero.

\section{Spatial population structure}

Prior research has shown variability in nesting fidelity ranging from a few meters to several hundred 
kilometers (Carr \& Carr 1972, Norman et al. 1994, Peare \& Parker 1996, Dethmers et al. 2006). In the case of Ascension Island, Carr (1975) reported that 22 out of 24 remigrants returned to nest at the same site where they were tagged. Mark-recapture analysis of reproductive homing by Mortimer \& Portier (1989) found evidence of high site fidelity to beach clusters for females laying different clutches within a season, and for females returning in successive seasons, with approximately 70 to $80 \%$ of tagged remigrants. However, our fine-scale sampling revealed shallow or nonstatistically significant pairwise differentiation among the 10 sampling sites and 4 beach clusters in Ascension Island. The data did not provide additional insights into beach clustering beyond the criteria suggested by Mortimer \& Portier (1989). As with many other species, a degree of fidelity may allow repeated exploitation of what are known to be favourable conditions, and is likely to be a function of distance between alternative nesting sites, as well as a result of environmental cues and imprinting. In Ascension, weak genetic structure suggests that nest site selection does not discriminate among island zones and philopatry does not appear to be driven by high site specificity. Hence, we were unable to conclusively attribute the apparent sitefidelity shown by tag returns, possibly determined by successful nesting attempts in previous seasons, to fine-scale natal homing instincts.

Bjorndal et al. (2005) did not detect spatial structure based on mitochondrial sequences within the Tortuguero rookery, with an even larger sample size than ours. However, previous work in Tortuguero using nuclear minisatellite markers had revealed spatial structure of genetically distinct lineages, with relatedness among nesting females decreasing with increasing separation on the nesting beach (Peare \& Parker 1996). The inability of mitochondrial markers to resolve structure in Tortuguero might be attributable to low variability (only 5 haplotypes in 433 samples), suggesting that we might expect the higher diversity in Ascension (13 haplotypes in 245 samples) to yield higher resolution. Indeed, we did detect some structure with a large sample size, but differentiation was weak and only among the 3 primary beaches, and may have been attributable to uneven sample sizes and/or variation in reproductive success between certain sites, rather than fine-scale philopatry. While it is possible that increased sample sizes at all beaches might show a more obvious pattern, analysis of this large sample set using more variable markers, such as microsatellites, might also yield less coarse structural resolution and may prove helpful in assessing levels of relatedness between neighbouring nests and between females nesting on the same beach. Lee et al. (2007) used 5 microsatellite loci to show weak but detectable assignment to 2 out of the 3 Ascension beaches tested and possible evidence of male-mediated gene flow, although traditional $F$-statistics did not detect any structure. We believe that a detailed study of reproductive success at each of the 10 sampling sites might also provide further insights into site preference patterns. In addition, an analysis of microsatellite markers should contribute insights into genetic bottlenecks the rookery may have suffered as a consequence of the harvest to which it has been subjected in the past 200 yr (Huxley 1999, Broderick et al. 2006), and reveal any effects this may have had on genetic structure and diversity. Ultimately, both nuclear and mitochondrial data are necessary to provide an accurate and comprehensive understanding of complex population structure, as shown by Bowen et al. (2005) for Atlantic loggerhead turtles Caretta caretta.

\section{Temporal population structure}

Often in phylogeographic studies, particularly when studying rare, endangered or elusive species, samples are pooled over several sampling periods or among years. However, it is conceivable that genetically different stocks may be present during different seasons or at different times within a season (Bjorndal et al. 2005), so pooling them at the time of analysis may lead to biased results. In addition, the high inter-annual variability of nesting abundance observed in green turtles (Broderick et al. 2001) might also lead to sampling error and may confound temporal structure in a population. We found no genetic differentiation among the samples collected during the 4 seasons of our study, suggesting that a pooled sample set over the entire time period is representative of the mtDNA diversity of the Ascension population as a whole. However, temporal analysis across long-term cycles of nesting abundance, as well as within one nesting season, represents avenues for future research, in order to further elucidate temporal genetic variability.

Interestingly, the Ascension haplotype frequencies found by Encalada et al. (1996) (3 haplotypes among 20 samples) are significantly different from subsequent samples, where we found 10 additional haplotypes (Table 4). The same did not occur in Tortuguero, where earlier analysis of 15 (Encalada et al. 1996) and 41 samples (Lahanas et al. 1998) did not exhibit significant differentiation from a subsequent increase in sampling over several seasons (Bjorndal et al. 2005). Although limited sample sizes over a single season may be adequate to describe haplotypic diversity in populations with low diversity such as Tortuguero, it is advisable to verify this by comparing at least 2 seasons of data. In the case of Ascension, we cannot exclude non-random 
sampling as a possible cause of differentiation among sampling efforts (we have no information on sampling dates and locations of Encalada's samples) or a hypothetical long-term temporal variation in genetic composition. However, the limited sample size of the first analysis associated with a substantially higher haplotype diversity later detected in the population appears to be a more likely explanation. Although we believe the probability of having resampled the individuals of Encalada et al. (1996) during our study is negligible, our analysis revealing significant genetic differentiation suggests it would be incorrect to pool their samples with the additional ones presented here into a single Ascension dataset. Hence, we recommend that only the 245 samples from the present study be used for successive analyses, such as phylogeographic comparisons or mixed stock analysis.

\section{Regional population structure}

The Ascension Island population shares mtDNA haplotypes with several rookeries in the eastern and western Atlantic (Lahanas et al. 1994, Encalada et al. 1996, Formia et al. 2006). Shared haplotypes may indicate gene flow due to occasional mistakes in natal homing, or may result from founder events and colonisation of new rookeries followed by insufficient time for divergence. Hence, we examined whether the Ascension rookery was significantly different from other Atlantic rookeries, and whether the level of divergence was affected by the Ascension sample size used in the analysis. We found that Ascension is highly divergent from all other Atlantic nesting populations so far profiled and that increased sampling had corrected the expected statistical error suffered as a result of early parsimonious sampling and analysis (Encalada et al. 1996). In fact, the 2 nearby rookeries of Bioko (Equatorial Guinea) and Rocas Atoll (Brazil) previously reported not to be significantly differentiated from Ascension Island were genetically divergent using the increased sample size. Pooling these rookeries in subsequent analyses, such as those estimating source contributions to mixed stocks (i.e. Lahanas et al. 1998, Bass et al. 2006), would be misleading and might lead to biased management recommendations. In addition, in the present study, we use a sample size for the Guinea Bissau rookery (Formia et al. 2006) greater than that used in previous phylogeographic studies (Encalada et al. 1996, Lahanas et al. 1998), which had incorrectly grouped this rookery together with Ascension Island. Our analysis reveals significant differentiation between Guinea Bissau and Ascension Island, suggesting that these 2 nesting populations should not be considered a single management unit.
Of the Ascension haplotypes, 11 out of 13 have also been identified among mixed aggregations at sea (Lahanas et al. 1998, Formia 2002, Bagley 2003, Luke et al. 2004, Naro-Maciel et al. 2007, Bjorndal et al. 2006), either in foraging grounds, or in migratory and developmental habitat, while only 2 have not yet been observed at any other rookeries (CM-A25 and CMA50). Both the common and rare Ascension haplotypes help establish overlap in frequency distributions between this rookery and mixed stocks elsewhere, and can help identify important links and define population distribution. For instance, among the more common haplotypes, CM-A6, CM-A8 and CM-A24 are present in both eastern and western Atlantic feeding grounds, CM-A8 being the most common haplotype throughout the south Atlantic region. In contrast, haplotype CM-A39 has only been found among rookeries in Ascension, and among foraging grounds in Corisco Bay (Equatorial Guinea/Gabon; Formia 2002). Haplotype CM-A44 has only been found in Brazilian and West African mixed stocks (Formia 2002, Naro-Maciel et al. 2007), while CM-A45 and CM-A46 have only been found in Brazilian foraging grounds (NaroMaciel et al. 2007). Statistical analyses, such as Bayesian mixed stock analysis (Pella \& Masuda 2001), can help estimate the contribution of the Ascension rookery to foraging populations. Mixed stock analysis calculations involve discarding foraging ground samples that exhibit haplotypes not attributable to any described source rookery. Hence, being able to assign rare haplotypes (such as CM-A39, CM-A44, CM-A45 and CM-A46) to a nesting population thanks to increased sampling prevents those haplotypes from being discarded when they appear in mixed stocks, and the information lost. However, while increasing the resolution of the analysis, rare haplotypes may also lead to overestimation of rookery contributions in mixed stocks, particularly if the potentially contributing rookeries have uneven sample sizes; the better sampled populations exhibiting the rare haplotypes found in the mixed stocks might be over-represented with respect to less well-sampled rookeries. The effects of increased Ascension Island sampling, rare haplotype detection and uneven rookery sample sizes on mixed stock analyses are the subject of ongoing studies and will be further discussed separately.

\section{Population sampling}

We evaluated the effect of increased sampling on our genetic description of the Ascension rookery. Haplotype and nucleotide diversities did not change substantially with increased sample size, although the confidence intervals were much narrower for haplo- 
type diversity, and thus likely to increase the statistical power of subsequent analysis. However, the large sample we analysed yielded 13 haplotypes, 10 more than the original sampling effort (Encalada et al. 1996). We found other common haplotypes such as CM-A6 and CM-A24, as well as 7 singletons and one haplotype present in 2 individuals. Next, we evaluated the proportion of captured diversity by estimating the total diversity occurring on Ascension through extrapolation of the rarefaction curve to its asymptote. Thus, we estimate that 18 haplotypes overall are likely to occur in the Ascension population. Since 245 samples represent less than $1 \%$ of the yearly nesting population (Broderick et al. 2006), detecting 13 of 18 haplotypes suggests a high power of detection for our sample size.

Of the 57 control region haplotypes described to date in the Atlantic (see http://accstr.ufl.edu/genetics.html), 16 have been found among mixed stocks at low frequencies, but have not been detected in any nesting population. Although this may indicate that there are undiscovered or unsampled nesting beaches, it is more likely the result of rookery sample sizes too small to detect rare haplotypes. In a study of American shad Alosa sapidissima Epifanio et al. (1995) found that approximately 70 samples were needed to detect $95 \%$ of haplotypes in a population. Contrary to shad, green turtle populations tend to exhibit one very common haplotype and several rare ones, whose detection requires larger sample sizes. Our analysis, for instance, estimates that 1384 samples would be necessary to detect $94 \%$ of the Ascension haplotypes. However, is the level of resolution provided by these very rare haplotypes likely to justify such extensive sampling effort? As mentioned above, rare haplotypes can indicate important links between well-described rookeries and foraging aggregations and can also contribute to resolving genetic differentiation between populations. When population differentiation statistics indicate that geographically distant rookeries are genetically uniform, an unexpected situation given female philopatric behaviour, it is particularly important to assess the adequacy of the sample sizes used in the analysis. However, study goals must be clearly evaluated when choosing to collect and analyse large sample sizes and the increased resolution balanced with increased effort and analysis costs.

We recommend carrying out a rarefaction analysis to estimate the proportion of variation described by the samples, hence assessing the desired sample size against haplotype diversity within the population. A population with low diversity such as Tortuguero might be adequately described by a smaller sample size than the more diverse Ascension Island rookery, irrespective of overall population size. For example, according to rarefaction extrapolations, it might require a near doubling of sampling effort at Tortuguero to increase resolution by detecting a single additional haplotype (5 haplotypes out of 6 estimated to occur), although some $83 \%$ of the haplotypic diversity might have been detected by only 167 samples. In Ascension, instead, around 430 samples would be needed in order to capture $83 \%$ of the diversity, or 15 out of the 18 haplotypes estimated to occur.

Given our sample size and the size of the nesting population in Ascension Island, we detected rarer haplotypes than predicted by GENESAMP, which might be attributed to a combination of chance, gene flow and the shallow population substructuring within the rookery (Barratt et al. 1999). GENESAMP predicted that we were less likely to identify very rare haplotypes than estimated by the rarefaction model. However, with respect to common haplotypes, there was greater agreement between rarefaction and GENESAMP. While the former analysis predicted we would observe 2 haplotypes with approximately 3 to 16 samples, the latter calculated that a sample size of at least 2 is needed to detect CM-A8 and 17 samples are needed to detect a second haplotype with $95 \%$ confidence. Taken together, these analyses highlight the fact that there are no set criteria specifying the best percentage of described diversity for a sampling effort, or the frequency of the rarest haplotype which should be detected in a population of a certain size. These will invariably depend on the goals and scale of the study being carried out, and should be considered carefully at the outset.

Large sample sizes are often difficult to obtain for highly endangered populations, for shy and elusive species or populations that are remote and logistically difficult to access. A common dilemma of conservation geneticists is determining the minimum sample size needed for phylogeographic studies of these endangered populations. One seeks a balance between the logistical and financial effort required to collect and process samples, and the need to describe a high proportion of the real variation. In the case of Atlantic green turtles, rookery sample sizes reported to date are very uneven, ranging from Tortuguero's 433 (Bjorndal et al. 2005) to as little as 6 samples from Principe Island (Formia et al. 2006). However, given that mtDNA control region analysis is routinely used in green turtle phylogeographic studies, we believe adequate sampling should be given high priority particularly in small and declining rookeries in order to capture their genetic diversity before it is further reduced by dwindling numbers. We also recommend using rarefaction analysis to provide a measure of confidence in the proportion of the total diversity being captured by the sample size, while GENESAMP can supply further insights into the detectability of 
rare or common alleles given the population size. Finally, it is important to consider ways to compensate for differences in sample size when carrying out comparisons of genetic diversity among populations. A major advantage of rarefaction analysis (and other subsampling methods) is that it can be used to evaluate sample sets collected using different sampling strategies, in unequal sizes, different regions or analysed with a different number of genes (Leberg 2002, Kalinowski 2004). All of these avenues warrant further attention.

\section{CONCLUSIONS}

We have confirmed the genetic uniqueness of the Ascension Island green turtle rookery and the need for its continued protection. The sample size of 245 genetic samples available from this population adequately documents haplotypic diversity and regional differentiation, accounting for observed levels of variation and population size. Following over 2 centuries of exploitation, Broderick et al. (2006) suggest that the Ascension Island nesting population is demonstrating significant recovery. However, despite being legally protected at the nesting site (Broderick et al. 2002), several threats affect Ascension turtles throughout their life cycle. Very little is known about the distribution and conservation status at migratory, developmental and feeding habitat for these turtles. Although Brazilian feeding grounds are relatively well protected from exploitation by coastal fishermen (Marcovaldi \& Marcovaldi 1999), other Atlantic waters are subject to heavy hunting pressure (Formia et al. 2003), particularly in West Africa, where recent genetic evidence suggests the presence of Ascension turtles (Formia 2002). We hope this study will provide a baseline for future descriptions of the full range of the Ascension nesting population.

It is clear that genetic diversity and sample sizes are important factors in detecting sufficient variation within an endangered marine turtle population, which in turn leads to increased accuracy and statistical power of mixed stock assessments of fisheries and foraging grounds of critical conservation relevance. We have shown that the adequacy of sample sizes should be assessed on a rookery-by-rookery basis, given the observed diversity, overall population size and any practical sampling constraints. In the case of Ascension, our study indicates that analysing more than 245 individuals would not likely add substantially to a description of haplotypic diversity, and we suggest that additional resources would be better spent on undersampled populations or on analyses using more variable molecular markers.
Acknowledgements. Fieldwork on Ascension Island was supported by grants from the Natural Environment Research Council of the UK (NERC), the Department of the Environment Transport and Regions (DETR) through their Darwin Initiative scheme and the Foreign and Commonwealth Office Environment Fund for the Overseas Territories. The field team thank the Ascension Island Turtle Group for their logistical support and the Administrators of Ascension Island, Roger Huxley and Geoffrey Fairhurst, for permission to conduct this work and their support during our stays on the island. For assistance with laboratory work and data analysis we are grateful to Gareth Lewis, Helen Wilcock, Ciara Dodd, Kath Jeffery, Silvio Carrettin and Paul Mcgeoghan. A.F. was supported by a European Union Marie Curie Training and Mobility of Researchers grant and B.J.G. by a NERC Fellowship. We thank 3 anonymous reviewers for their comments on an earlier draft of this manuscript.

\section{LITERATURE CITED}

Allard MW, Miyamoto MM, Bjorndal KA, Bolten AB, Bowen BW (1994) Support for natal homing in green turtles from mitochondrial DNA sequences. Copeia 1994:34-41

Allen M, Engstrom AS, Meyers S, Handt O, Saldeen T, von Haeseler A, Pääbo S, Gyllensten U (1998) Mitochondrial DNA sequencing of shed hairs and saliva on robbery caps: sensitivity and matching probabilities. J Forensic Sci 43: 453-464

Altmann J, Alberts SC, Haines SA, Dubach J and 9 others (1996) Behavior predicts genetic structure in a wild primate group. Proc Natl Acad Sci USA 93:5797-5801

Bagley DA (2003) Characterizing juvenile green turtles (Chelonia mydas) from three east central Florida developmental habitats. MS thesis, University of Central Florida, Orlando, FL

Baillie JEM, Hilton-Taylor C, Stuart SN (eds) (2004) 2004 IUCN red list of threatened species. A global species assessment. IUCN, Gland; available at: www.iucn.org/ themes/ssc/red_list_2004/main_EN.htm

Barratt EM, Gurnell J, Marky G, Deaville R, Bruford MW (1999) Genetic structure of fragmented populations of red squirrel (Sciurus vulgaris) in the UK. Mol Ecol 8:S55-S63

Bass AL, Witzell WN (2000) Demographic composition of immature green turtles (Chelonia mydas) from the East Central Florida coast: evidence from mtDNA markers. Herpetologica 56:357-367

Bass AL, Lagueux CJ, Bowen BW (1998) Origin of green turtles, Chelonia mydas, at sleeping rooks off the northeast coast of Nicaragua. Copeia 1998:1064-1069

Bass AL, Epperly SP, Braun-McNeill JB (2006) Green turtle (Chelonia mydas) foraging and nesting aggregations in the Caribbean and Atlantic: impact of currents and behavior on dispersal. J Hered 97:346-354

Bernatchez L, Dodson JJ, Boivin S (1989) Population bottlenecks: influence on mitochondrial DNA diversity and its effect in coregonine stock discrimination. J Fish Biol 35A:233-244

Bjorndal KA, Bolten AB, Troeng S (2005) Population structure and genetic diversity in green turtles nesting at Tortuguero, Costa Rica, based on mitochondrial DNA control region sequences. Mar Biol 147:1449-1457

Bjorndal KA, Bolten AB, Moreira L, Bellini C, Marcovaldi MA (2006) Population structure and diversity of Brazilian green turtle rookeries based on mitochondrial DNA sequences. Chelonian Conserv Biol 5:262-268

Bowen BW, Meylan AB, Avise JC (1989) An odyssey of the 
green turtle: Ascension Island revisited. Proc Natl Acad Sci USA 86:573-576

Bowen BW, Meylan AB, Ross JP, Limpus CJ, Balazs GH, Avise JC (1992) Global poulation structure and natural history of the green turtle (Chelonia mydas) in terms of matriarchal phylogeny. Evolution 46:865-881

Bowen BW, Kamezaki N, Limpus CJ, Hughes GR, Meylan AB, Avise JC (1994) Global phylogeography of the loggerhead turtle (Caretta caretta) as indicated by mitochondrial DNA haplotypes. Evolution 48:1820-1828

Bowen BW, Abreu-Grobois FA, Balazs GH, Kamezaki N, Limpus CJ, Ferl RJ (1995) Trans-Pacific migrations of the loggerhead turtle (Caretta caretta) demonstrated with mitochondrial DNA markers. Proc Natl Acad Sci USA 92: 3731-3734

Bowen BW, Clark AM, Abreu-Grobois FA, Chaves A, Reichart HA, Ferl RJ (1998) Global phylogeography of the ridley sea turtles (Lepidochelys spp.) as inferred from mitochondrial DNA sequences. Genetica 101:179-189

Bowen BW, Bass AL, Soares L, Toonen RJ (2005) Conservation implications of complex population structure: lessons from the loggerhead turtle (Caretta caretta). Mol Ecol 14: 2389-2402

Broderick AC, Godley BJ, Hays GC (2001) Trophic status drives inter-annual variability in nesting numbers of marine turtles. Proc R Soc Lond B 268:1481-1487

Broderick AC, Glen F, Godley BJ, Hays GC (2002) A management plan for the marine turtles of Ascension Island. Marine Turtle Research Group, available at www.seaturtle.org/mtrg/projects/ascension/mplan.shtml

Broderick AC, Frauenstein R, Glen F, Hays GC, Jackson AL, Pelembe T, Ruxton GD, Godley BJ (2006) Are green turtles globally endangered? Global Ecol Biogeogr 35:21-26

Carr A (1975) The Ascension Island green turtle colony. Copeia 3:547-555

Carr A, Carr MH (1972) Site fixity in the Caribbean green turtle. Ecology 53:425-429

Carr A, Coleman PJ (1974) Seafloor spreading theory and the odyssey of the green turtle. Nature 249:12-130

Carr A, Hirth H (1962) The ecology and migrations of sea turtles, 5. Comparative features of isolated green turtle colonies. Am Mus Novit 2091:1-42

Clement M, Posada D, Crandall KA (2000) TCS: a computer program to estimate gene genealogies. Mol Ecol 9: $1657-1660$

Colwell RK, Coddingtion JA (1994) Estimating terrestrial biodiversity through extrapolation. Phil Trans R Soc Lond B Biol Sci 345:101-118

Dethmers KEM, Broderick D, Moritz C, FitzSimmons NN and 6 others (2006) The genetic structure of Australasian green turtles (Chelonia mydas): exploring the geographical scale of genetic exchange. Mol Ecol 15:3931-3946

Duncan KM, Martin AP, Bowen BW, Couet HG (2006) Global phylogeography of the scalloped hammerhead shark (Sphyrna lewini). Mol Ecol 15:2239-2251

Dutton PH (1996) Methods for collection and preservation of samples for sea turtle genetic studies. In: Bowen BW, Witzell WN (eds) Proceedings of the International Symposium on Sea Turtle Conservation Genetics. NOAA Tech Memo NMFS-SEFSC-396, US Department of Commerce, Miami, FL, p 17-24

Dutton PH, Bowen BW, Owens DW, Barragan A, Davis SK (1999) Global phylogeography of the leatherback turtle (Dermochelys coriacea). J Zool 248:397-409

Encalada SE, Lahanas PN, Bjorndal KA, Bolten AB, Miyamoto MM, Bowen BW (1996) Phylogeography and population structure of the Atlantic and Mediterranean green turtle
Chelonia mydas: a mitochondrial DNA control region sequence assessment. Mol Ecol 5:473-483

Epifanio JM, Smouse PE, Kobak CJ, Brown BL (1995) Mitochondrial DNA divergence among populations of American shad (Alosa sapidissima): how much variation is enough for mixed-stock anlysis? Can J Fish Aquat Sci 52: $1688-1702$

Escorza-Treviño S, Dizon AE (2000) Phylogeography, intraspecific structure and sex-biased dispersal of Dall's porpoise, Phocoenoides dalli, revealed by mitochondrial and microsatellite DNA analyses. Mol Ecol 9:1049-1060

Excoffier L, Smouse PE, Quattro JM (1992) Analysis of molecular variance inferred from metric distances among DNA haplotypes: application to mitochondrial DNA restriction data. Genetics 131:479-491

Formia A (2002) Population and genetic structure of the green turtle (Chelonia mydas) in West and Central Africa; implications for management and conservation. PhD thesis, Cardiff University

Formia A, Tiwari M, Fretey J, Billes A (2003) Sea turtle conservation along the Atlantic coast of Africa. Mar Turt Newsl 100:33-37

Formia A, Godley BJ, Dontaine JF, Bruford MW (2006) Mitochondrial DNA diversity and phylogeography in African green turtles (Chelonia mydas). Conserv Genet 7:353-369

Godley BJ, Broderick AC, Hays GC (2001) Nesting of green turtles (Chelonia mydas) at Ascension Island, South Atlantic. Biol Conserv 97:151-158

Graves JE (1998) Molecular insights into the population structures of cosmopolitan marine fishes. J Hered 89:427-437

Hays GC, Akesson S, Broderick AC, Glen F, Papi F, Luschi P (2003) Island-finding ability of marine turtles. Proc R Soc Lond B Biol Sci 270:S5-S7

Hebert PDN, Ward RD, Weider LJ (1988) Clonal-diversity patterns and breeding-system variation in Daphnia pulex, a asexual-sexual complex. Evolution 42:147-159

Hirth HF (1997) Synopsis of biological data on the green turtle Chelonia mydas (Linnaeus) 1758. US Fish Wildl Serv Biol Rep 97-1

Hurlbert SH (1971) The nonconcept of species diversity: a critique and alternative parameters. Ecology 52:577-586

Huxley R (1999) Historical overview of marine turtle exploitation on Ascension Island, South Atlantic, 1999. Mar Turt Newsl 84:7-9

Kalinowski ST (2004) Counting alleles with rarefaction: private alleles and hierarchical sampling designs. Conserv Genet 5:539-543

Kimura M (1980) A simple method for estimating evolutionary rates of base substitutions through comparative studies of nucleotide sequences. J Mol Evol 16:111-120

Koch AL, Carr A, Ehrenfeld DW (1969) The problem of opensea navigation: the migration of the green turtle to Ascension Island. J Theor Biol 22:163-179

Kohn MH, York EC, Kamradt DA, Haught G, Suvajot RM, Wayne RK (1999) Estimating population size by genotyping faeces. Proc R Soc Lond B Biol Sci 266:657-663

Kumazawa Y, Nishida M (1999) Complete mitochondrial DNA sequences of the green turtle and blue-tailed mole skink: statistical evidence for archosaurian affinity of turtles. Mol Biol Evol 16:784-792

Lahanas PN, Miyamoto MM, Bjorndal KA, Bolten AB (1994) Molecular evolution and population genetics of Greater Caribbean green turtles (Chelonia mydas) as inferred from mitochondrial DNA control region sequences. Genetica 94:57-67

Lahanas PN, Bjorndal KA, Bolten AB, Encalada SE, Miyamoto MM, Valverde RA, Bowen BW (1998) Genetic composition 
of a green turtle (Chelonia mydas) feeding ground population: evidence for multiple origins. Mar Biol 130:345-352

Laurent L, Casale P, Bradai MN, Godley BJ and 14 others (1998) Molecular resolution of marine turtle stock composition in fishery bycatch: a case study in the Mediterranean. Mol Ecol 7:1529-1542

Leberg PL (2002) Estimating allelic richness: effects of sample size and bottlenecks. Mol Ecol 11:2445-2449

Lee PLM, Luschi P, Hays GC (2007) Detecting female precise natal philopatry in green turtles using assignment methods. Mol Ecol 16:61-74

Le Gall JY, Hughes GR (1987) Migrations de la tortue verte Chelonia mydas dans l'Océan Indien Sud-Ouest observées à partir des marquages sur les sites de ponte Europa et Tromelin (1970-1985). Amphibia-Reptilia 8: 277-282

Lehman N, Wayne RK (1991) Analysis of coyote mitochondrial DNA genotype frequencies: estimation of the effective number of alleles. Genetics 128:405-416

Lohmann KJ, Cain SD, Dodge SA, Lohmann CMF (2001) Regional magnetic fields as navigational markers for sea turtles. Science 294:364-366

Luke K, Horrocks JA, LeRoux RA, Dutton PH (2004) Origins of green turtle (Chelonia mydas) feeding aggregations around Barbados, West Indies. Mar Biol 144:799-805

Luschi P, Hays GC, Del Seppia C, Marsh R, Papi F (1998) The navigational feats of green sea turtles migrating from Ascension Island investigated by satellite telemetry. Proc R Soc Lond B Biol Sci 265:2279-2284

Marcovaldi MA, Marcovaldi GG (1999) Marine turtles in Brazil: the history and structure of Projecto TAMARIBAMA. Biol Conserv 91:35-41

Meylan AB, Bowen BW, Avise JC (1990) A genetic test of the natal homing versus social facilitation models for green turtle migration. Science 248:724-727

Miller J (1997) Reproduction in sea turtles. In: Lutz PL, Musick JA (eds) The biology of sea turtles. CRC Press, Boca Raton, FL, p 51-81

Milligan BG (1998) Total DNA isolation. In: Hoelzel AR (ed) Molecular genetic analysis of populations, a practical approach, 2nd edn. IRL Press, Oxford, p 29-64

Mortimer JA, Carr A (1987) Reproduction and migrations of the Ascension Island green turtle (Chelonia mydas). Copeia 1987:103-113

Mortimer JA, Portier KM (1989) Reproductive homing and internesting behaviour of the green turtle (Chelonia mydas) at Ascension Island, South Atlantic Ocean. Copeia 1989:962-977

Musick JA, Limpus CJ (1997) Habitat utilisation and migration in juvenile sea turtles. In: Lutz PL, Musick JA (eds) The biology of sea turtles. CRC Press, Boca Raton, FL, p 137-165

Naro-Maciel E, Becker JH, Lima EHSM, Marcovaldi MA, DeSalle R (2007) Testing dispersal hypotheses in foraging

Editorial responsibility: Stephen Rossiter,

London, UK green sea turtles (Chelonia mydas) of Brazil. J Hered 98: 29-39

Norman JA, Moritz C, Limpus CJ (1994) Mitochondrial DNA control region polymorphisms: genetic markers for ecological studies of marine turtles. Mol Ecol 3:363-373

O'Corry-Crowe GM, Suydam RS, Rosenberg A, Frost KJ, Dizon AE (1997) Phylogeography, population structure and dispersal patterns of the beluga whale Delphinapterus leucas in the western Nearctic revealed by mitochondrial DNA. Mol Ecol 6:955-970

Papi F, Liew HC, Luschi P, Chan EH (1995) Long-range migratory travel of a green turtle tracked by satellite: evidence for navigational ability in the open sea. Mar Biol 122:171-175

Papi F, Luschi P, Akesson S, Capogrossi S, Hays GC (2000) Open-sea migration of magnetically disturbed sea turtles. J Exp Biol 203:3435-3443

Peare T, Parker PG (1996) Local genetic structure within two rookeries of Chelonia mydas (the green turtle). Heredity 77:619-628

Pella J, Masuda M (2001) Bayesian methods for analysis of stock mixtures from genetic characters. Fish Bull 99:151-167

Plotkin P (2003) Adult migrations and habitat use. In: Lutz PL, Musick JA (eds) The biology of sea turtles, Vol II. CRC Press, Boca Raton, FL, p 225-342

Rice WR (1989) Analyzing tables of statistical tests. Evolution 43:223-225

Rosel PE, France SC, Wang JY, Kocher TD (1999) Genetic structure of harbour porpoise Phocoena phocoena populations in the northwest Atlantic based on mitochondrial and nuclear markers. Mol Ecol 8:S41-S54

Sanders HL (1968) Marine benthic diversity: a comparative study. Am Nat 102:243-282

Schneider S, Roessli D, Excoffier L (2000) Arlequin ver. 2.000: a software for population genetics data analysis. Genetics and Biometry Laboratory, University of Geneva

Seminoff J (2004) 2004 global status assessment - green turtle (Chelonia mydas). Marine Turtle Specialist Group, The World Conservation Union (IUCN), Species Survival Commission, Red List Programme. Available at www.iucn-mtsg.org/red_list/cm/MTSG_Chelonia_mydas_ assessment_expanded-format.pdf

Simberloff D (1972) Properties of the rarefaction diversity measurement. Am Nat 106:414-418

Simberloff D (1978) Use of rarefaction and related methods in ecology. In: Dickson KL, Cairns J Jr, Livingston RJ (eds) Biological data in water pollution assessment: quantitative and statistical analyses. American Society for Testing and Materials, Philadelphia, PA, p 150-165

Sjögren P, Wyöni PI (1994) Conservation genetics and detection of rare alleles in finite populations. Conserv Biol 8: 267-270

Weir BS, Cockerham CC (1984) Estimating F-statistics for the analysis of population structure. Evolution 38:1358-1370

Submitted: October 21, 2006; Accepted: June 19, 2007

Proofs received from author(s): July 27, 2007 